\title{
Back to Normal - Normalised Left Ventricular Systolic Function in Dilated Cardiomyopathy after Cardiac Contractility Modulation Therapy
}

\author{
Laurens Bon, ${ }^{1}$ Bernhard M Kaess, ${ }^{1,2}$ Andre Hochgesand, ${ }^{1}$ Albrecht Römer, ${ }^{1}$ Gerd Bürkle ${ }^{1}$ and Joachim R Ehrlich ${ }^{1,3}$ \\ 1. Division of Cardiology, St Josefs-Hospital, Wiesbaden, Germany; 2. Deutsches Herzzentrum, Munich, Germany; 3. Division of Cardiology, \\ Goethe-University, Frankfurt, Germany
}

W e present a clinical case of a patient with dilated cardiomyopathy who neither sufficiently responded to optimal medical therapy nor to cardiac resynchronisation therapy. A cardiac contractility modulation system was implanted and after 2 years of combined therapy with medication and devices systolic left ventricular ejection fraction returned to near normal values.

\section{Keywords}

Cardiomyopathy, cardiac contractility modulation therapy, heart failure, cardiac resynchronisation therapy

Disclosure: Joachim R Ehrlich has received speaker and advisor honoraria from Impulse Dynamics. Laurens Bon, Bernhard M Kaess, Andre Hochgesand, Albrecht Römer and Gerd Bürkle have nothing to declare in relation to this article. Review Process: Double-blind peer review. Compliance with Ethics: All procedures were followed in accordance with the responsible committee on human experimentation and with the Helsinki Declaration of 1975 and subsequent revisions, and informed consent was received from the patient involved in this case study.

Authorship: All named authors meet the International Committee of Medical Journal Editors (ICMJE) criteria for authorship of this manuscript, take responsibility for the integrity of the work as a whole, and have given final approval to the version to be published.

open Access: This article is published under the Creative Commons Attribution Noncommercial License which permits any non-commercial use, distribution, adaptation and reproduction provided the original author(s) and source are given appropriate credit. (c) The Authors 2018.

Received: 31 July 2017

Accepted: 13 November 2017

Citation: European Journal of Arrhythmia

\& Electrophysiology. 2018;4(1):25-27

Corresponding Author: Joachim R Ehrlich, Division of Cardiology, St Josefs-Hospital, Beethovenstr. 20, 65189 Wiesbaden, Germany. E: joachimehrlich@t-online.de

The video content mentioned in this article is available at www.touchCARDIO.com

Support: No funding was received in

the publication of this article.

\section{Case Report}

We report on a 53-year-old man with a history of heart failure due to alcoholic dilated cardiomyopathy with severely depressed systolic left ventricular (LV) function. Initial LV ejection fraction was $20 \%$ (Simpson's biplane method, Loops 1 and 2). At the time of diagnosis his clinical status was New York Heart Association (NYHA) III-IV and he had left bundle branch block. Cardiac resynchronisation therapy (CRT) was initiated after ramipril, bisoprolol and spironolactone had been established for $>6$ months, intermittent use of loop diuretics was necessary.

The patient did not respond sufficiently to optimal treatment including CRT despite adequate LV lead position (echocardiogram, Figure 1, Loops 3 and 4). Cardiac contractility modulation (CCM) therapy was initialised by implantation of an Optimizer IV system ${ }^{\mathrm{TM}}$ (Impulse Dynamics, Loops 7 and 8, Figure 2). Over a period of 16 months, NYHA class as well as systolic LV function normalised (Figure 1, Loops 5 and 6). Settings for CCM were $30 \mathrm{~ms}$ after ventricular sensing, biphasic current of $7.5 \mathrm{~V}$ amplitude and $21 \mathrm{~ms}$ duration. Of note, the patient continued alcohol abuse.

\section{Discussion}

CCM pacing utilises electrical currents to enhance myocardial contractility in heart failure patients. Relatively high (5-7.5 V) voltage impulses are delivered during the absolute ventricular refractory period, after sensing ventricular depolarisation. These currents do not stimulate local ventricular depolarisation, rather they modulate the calcium flux into the myocyte. ${ }^{1}$ Modulating this calcium flux affects action potential, peak intracellular calcium, increases sarcoplasmic reticulum calcium partly due to influencing phospholamban phosphorylation and altered gene expression. ${ }^{1}$ These cellular changes may lead to local and remote reverse remodelling. ${ }^{1}$

The largest prospective randomised trial ${ }^{2}$ in heart failure patients (NYHA III-IV) with reduced LV ejection fraction $(<35 \%)$ treated with CCM demonstrated improved quality of life and improved peak VO2 as a measure for exercise tolerance but failed to meet its primary endpoint (change in anaerobic threshold).

Long-term follow-up (>1 year) from prospective randomised trials is lacking for patients treated with CCM. Our case demonstrates improvement in LV function with CCM after 16 months in a patient with insufficient response to CRT. CCM treatment of CRT nonresponders has been described in a series of patients. ${ }^{3}$ However, previous trials excluded patients with wide QRS or CRT, there is no randomised trial in patients with CRT. This case suggests positive long-term effects of CCM therapy on top of standard therapy for heart failure patients with reduced LV ejection fraction not responsive to CRT. $\square$ 
Loop 1: Two-chamber echocardiographic view at baseline

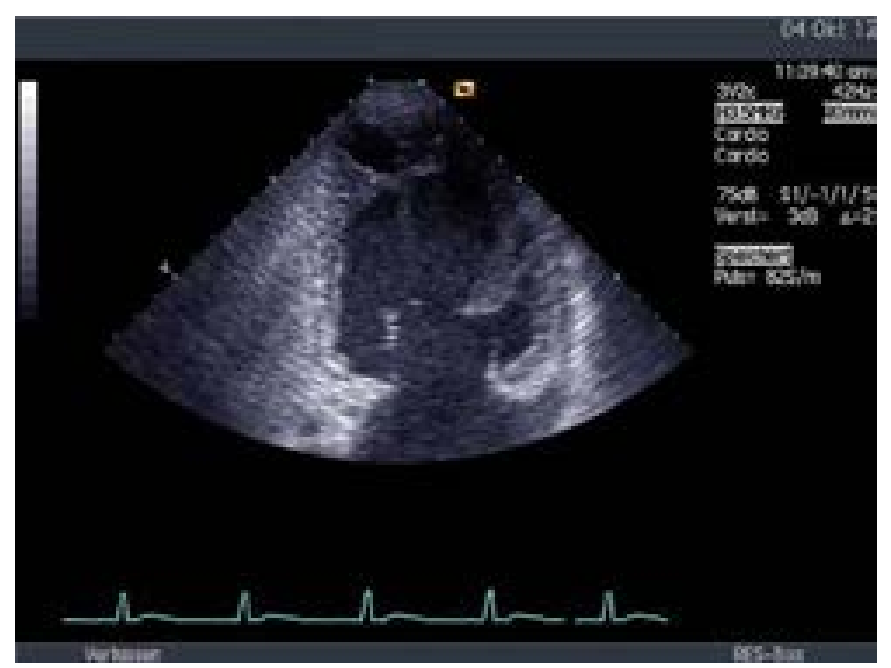

Figure 1: Changes in New York Heart Association functional class and left ventricular ejection fraction over time

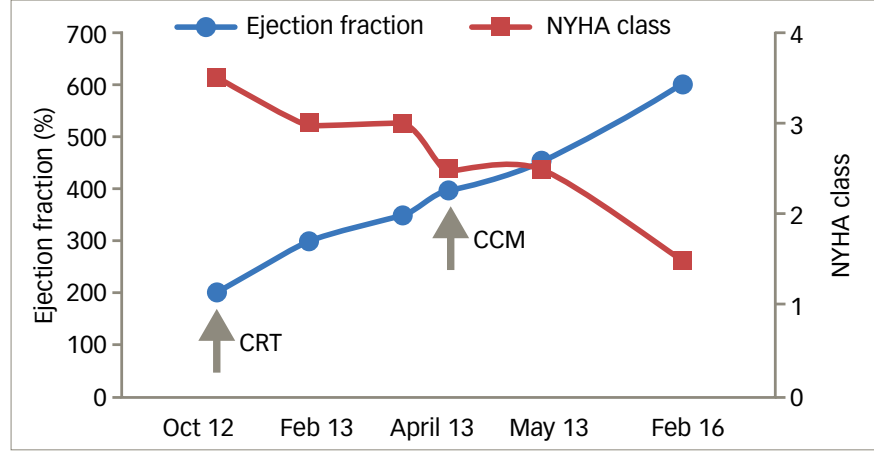

$C C M=$ cardiac contractility modulation; $C R T=$ cardiac resynchronisation therapy; NYHA $=$ NeW York Heart Association

Loop 3: After 6 months of cardiac resynchronisation therapy

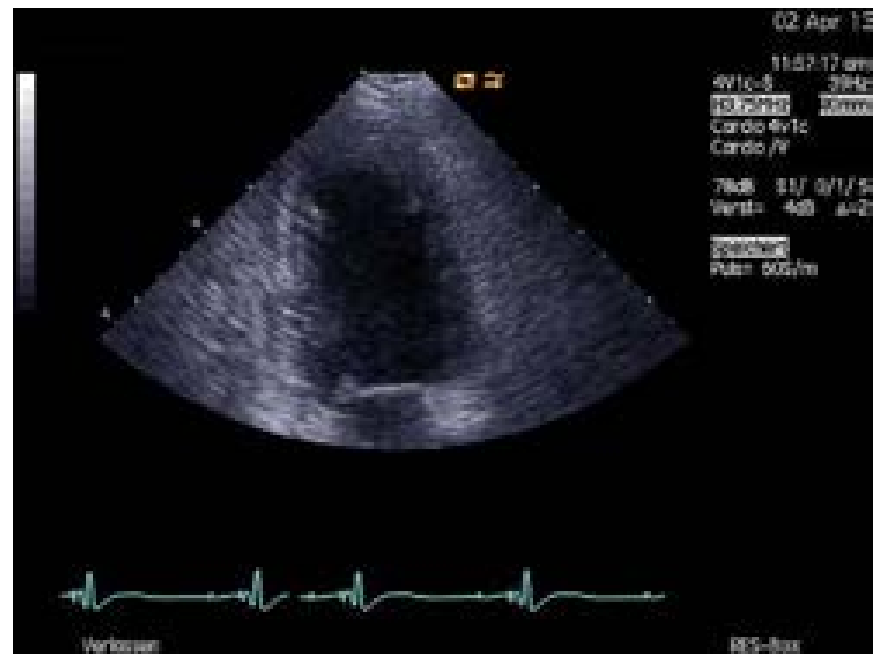

Loop 2: Four-chamber echocardiographic view at baseline

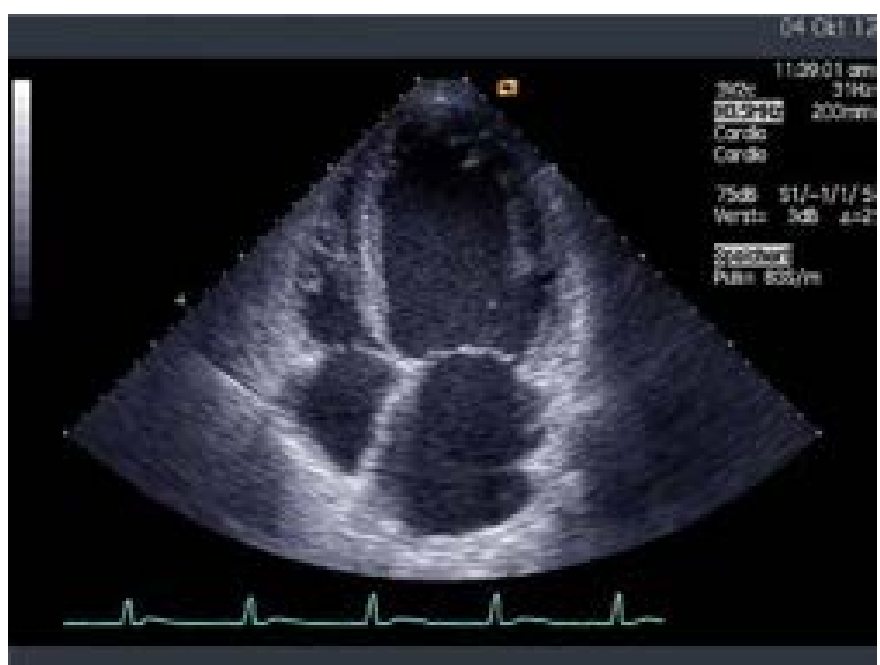

Figure 2: Anterior-posterior chest X-ray in obtained 03/2016 illustrating positions of cardiac contractility modulation leads in relation to cardiac resynchronisation therapy defibrillator leads

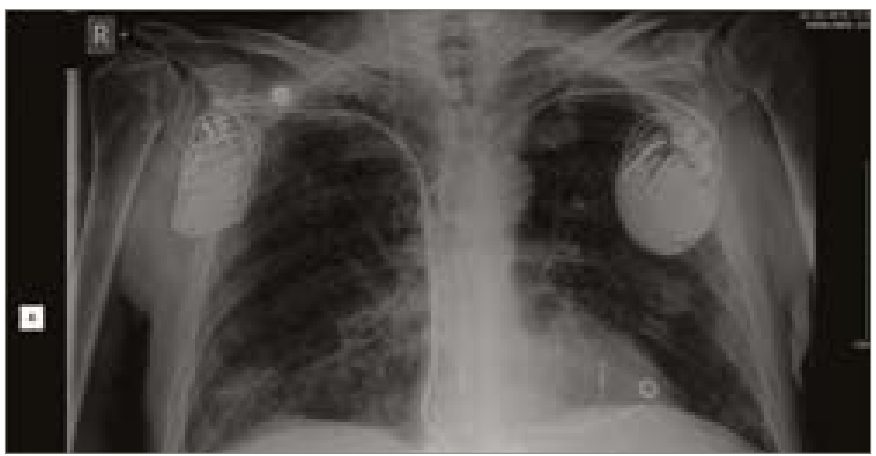

Loop 4: After 6 months of cardiac resynchronisation therapy

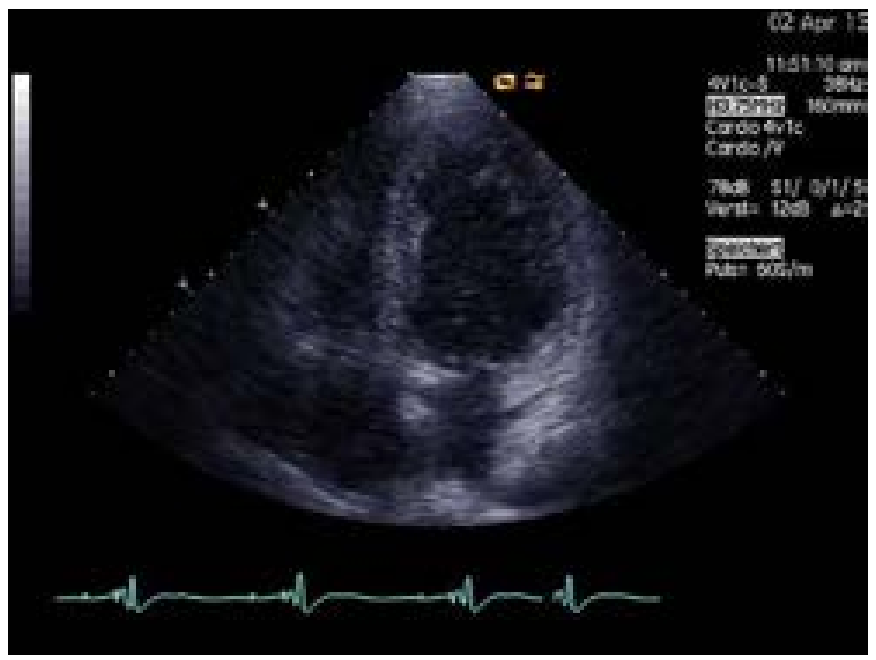


Loop 5: Normalised left ventricular function after 16 months of cardiac contractility modulation therapy

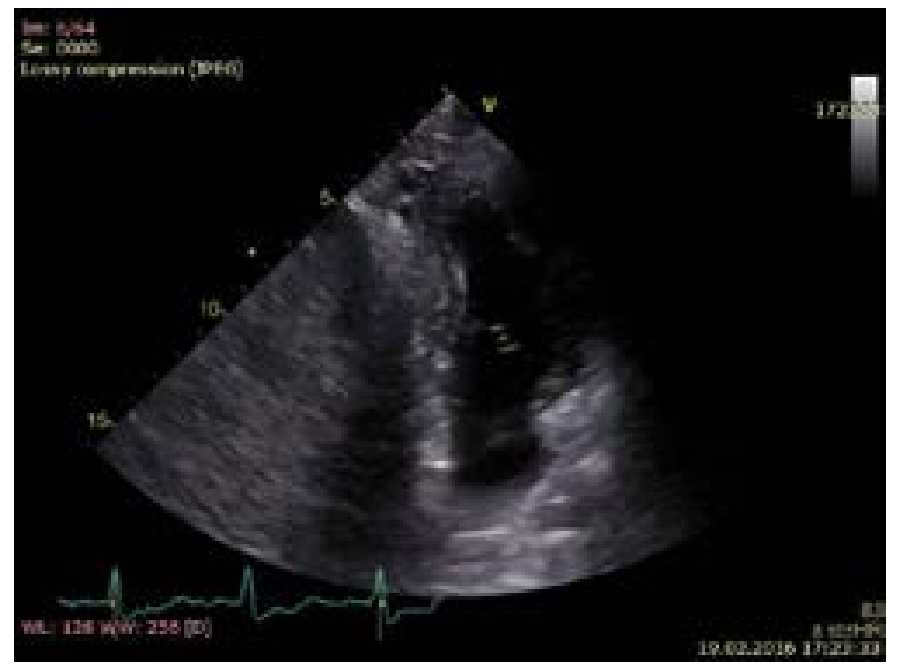

Loop 7: Lead position in right anterior oblique view at cardiac contractility modulation implant

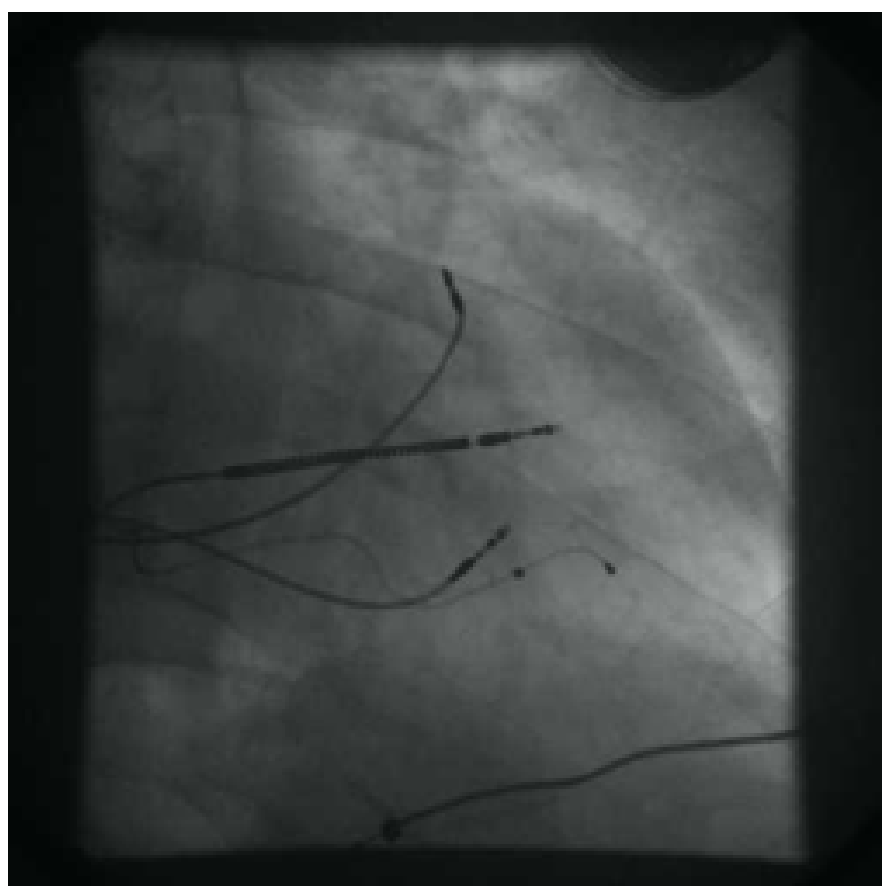

Loop 8: Lead position in left anterior oblique view at cardiac contractility modulation implant

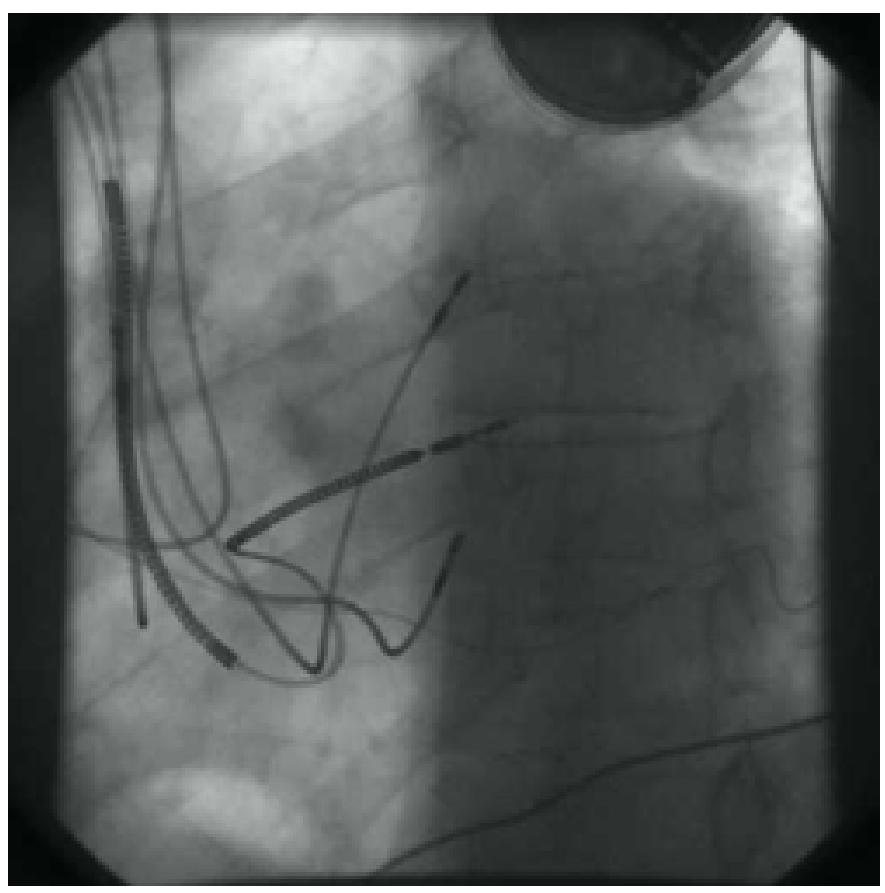

1. Lyon AR, Samara MA, Feldman DS. Cardiac contractility modulation therapy in advanced systolic heart failure. Nature Reviews Cardiology. 2013;10:584-98.

2. Kadish A, Nademanee K, Volosin K, et al. A randomized controlled trial evaluating the safety and efficacy of cardiac contractility modulation in advanced heart failure. Am Heart J. 2011;161:329-37.

3. Naegele H, Behrens S, Eisermann C. Cardiac contractility modulation in non-responders to cardiac resynchronization therapy. Europace. 2008;10:1375-80. 